\title{
Protein-based signatures of functional evolution in Plasmodium falciparum
}

Kate B Gardner ${ }^{1,2}$, Ipsita Sinha', Leyla Y Bustamante ${ }^{3}$, Nicholas PJ Day ${ }^{1}$, Nicholas J White ${ }^{1}$ and Charles J Woodrow ${ }^{1 *}$

\begin{abstract}
Background: It has been known for over a decade that Plasmodium falciparum proteins are enriched in nonglobular domains of unknown function. The potential for these regions of protein sequence to undergo high levels of genetic drift provides a fundamental challenge to attempts to identify the molecular basis of adaptive change in malaria parasites.

Results: Evolutionary comparisons were undertaken using a set of forty $P$. falciparum metabolic enzyme genes, both within the hominid malaria clade (P. reichenowi) and across the genus (P. chabaudi). All genes contained coding elements highly conserved across the genus, but there were also a large number of regions of weakly or non-aligning coding sequence. These displayed remarkable levels of non-synonymous fixed differences within the hominid malaria clade indicating near complete release from purifying selection (dN/dS ratio at residues nonaligning across genus: $0.64, \mathrm{dN} / \mathrm{dS}$ ratio at residues identical across genus: 0.03 ). Regions of low conservation also possessed high levels of hydrophilicity, a marker of non-globularity. The propensity for such regions to act as potent sources of non-synonymous genetic drift within extant $P$. falciparum isolates was confirmed at chromosomal regions containing genes known to mediate drug resistance in field isolates, where 150 of 153 amino acid variants were located in poorly conserved regions. In contrast, all 22 amino acid variants associated with drug resistance were restricted to highly conserved regions. Additional mutations associated with laboratoryselected drug resistance, such as those in PfATPase4 selected by spiroindolone, were similarly restricted while mutations in another calcium ATPase (PFSERCA, a gene proposed to mediate artemisinin resistance) that reach significant frequencies in field isolates were located exclusively in poorly conserved regions consistent with genetic drift.

Conclusion: Coding sequences of malaria parasites contain prospectively definable domains subject to neutral or nearly neutral evolution on a scale that appears unrivalled in biology. This distinct evolutionary landscape has potential to confound analytical methods developed for other genera. Against this tide of genetic drift, polymorphisms mediating functional change stand out to such an extent that evolutionary context provides a useful signal for identifying the molecular basis of drug resistance in malaria parasites, a finding that is of relevance to both genome-wide and candidate gene studies in this genus.
\end{abstract}

\section{Background}

Identifying the molecular basis of disease-causing traits is one of the major justifications for the recent expansion in genomic data covering a wide range of taxa. Nowhere is this goal more clearly defined than in the case of malaria, where adaptive evolution in the form of

\footnotetext{
* Correspondence: charlie@tropmedres.ac

'Wellcome Trust Mahidol University-Oxford Tropical Medicine Research Unit (MORU), 420/6 Rajwithi Road, Bangkok, 10400 Thailand

Full list of author information is available at the end of the article
}

drug resistance continues to undermine efforts to control human disease caused by $P$. falciparum [1] and $P$. vivax [2]. Understanding the molecular basis of resistance phenotypes is of great operational importance as markers can be used to monitor spread and alternative therapeutic strategies can be designed. Establishment of a genetic cross has proven a fruitful starting point for determination of the genotypic basis of drug resistance [3-5], but is difficult, expensive and hence rarely achieved in practice. Genomic epidemiological
C Biomed Central

() 2011 Gardner et al; licensee BioMed Central Ltd. This is an Open Access article distributed under the terms of the Creative Commons Attribution License (http://creativecommons.org/licenses/by/2.0), which permits unrestricted use, distribution, and reproduction in any medium, provided the original work is properly cited. 
approaches currently represent a promising route forward allowing detection of signatures of selection associated with drug resistance [6], although this approach relies on identification of linkage disequilibrium which is known to be of variable strength [7]. Candidate gene approaches based on other forms of data analysis may also generate hypotheses suitable for further testing $[8,9]$.

Despite the power of these approaches for the discovery of new drug-resistance genotypes, a decade has passed since the description of the last confirmed resistance gene for a widely used antimalarial [4]. It remains exceptional for mutations hypothesized as being involved in drug-resistance to be validated by transfection and phenotypic testing in P. falciparum, steps that allow polymorphisms of true adaptive value to be discriminated from those that are present simply as a result of genetic drift.

A specific phenomenon that may complicate studies in this genus relates to the remarkable degree to which Plasmodium proteins are enriched in non-globular domains [10]. Since their first systematic description more than a decade ago, the function of these domains has remained unresolved [11-13] with one possibility being that they represent downstream consequences of events at the DNA level (i.e. broadly neutral in functional terms). If this were to be the case, they would represent potent generators of neutral or near neutral non-synonymous polymorphism in line with central concepts of modern evolutionary biology [14-16] that will inevitably confound both genome-wide and candidate approaches to identifying the molecular basis of resistance. Notably, minimal attempts have been made to determine systematically the degree to which specific areas of coding sequence have become released from negative selective in the long-term, and by inference unlikely to mediate functional change in the short-term. Measurement of selective forces is still generally undertaken at a whole-gene level, an approach that falls down if pressures vary considerably within individual genes, preventing determination of the true baseline for variation which is neutral evolution within and between malaria species.

We reasoned that application of two basic biological concepts could improve significantly the accuracy of approaches designed to identify the genetic basis of drug-resistance. Firstly, drug resistance, by necessity, requires a significant functional change in the parasite, and hence a functional change in one or more proteins. Secondly, functionally important regions of proteins are generally conserved across wide distances of evolution, and can therefore be discriminated in orthologous sequence alignments from sequences under minimal constraint [17].
We undertook a systematic study of evolutionary processes in Plasmodium coding sequences, revealing widespread, dynamic variation in selection pressures within individual coding sequences consistent with neutral theories of evolution. The use of underlying conservation score as an independent means of identifying functional variation against the backdrop of genetic drift was validated and applied by examining the molecular basis of drug-resistance, a phenotype that, by necessity, requires a significant functional change in the parasite, and hence frequently a functional change in one or more proteins.

\section{Results}

Polymorphism and divergence: whole-gene level

In order to study short-term evolutionary processes within the hominid malaria clade a reference set of 40 $P$. falciparum genes (Table 1) was identified, consisting of sequences well covered by genome sequencing of the closely related primate parasite $P$. reichenowi [18]. Single-nucleotide changes in these genes associated with divergence (between P. falciparum 3D7 strain and $P$. reichenowi) and intra-species polymorphism (within sequenced $P$. falciparum isolates) were quantified. The 40-gene reference set contained 1270 fixed synonymous differences between $P$. falciparum and P. reichenowi indicating a synonymous pairwise divergence (dS) of $6.05 \%$, a figure consistent with previous estimates [19]. There were 795 non-synonymous fixed differences $(\mathrm{dN}$ $=0.92 \%$ ) indicating an overall $\mathrm{dN} / \mathrm{dS}$ ratio of 0.17 , consistent with broad negative selection across these genes. This compares to a genome-wide assessment of fixed differences between $P$. falciparum and $P$. reichenowi, $\mathrm{dN} / \mathrm{dS}=0.21$, and indicates that the sequences chosen broadly capture the range of $\mathrm{dN} / \mathrm{dS}$ ratios encountered in the P. falciparum genome [18]. Within sequenced $P$. falciparum isolates there were 83 synonymous and 102 non-synonymous polymorphisms ( $\mathrm{dN} / \mathrm{dS}$ ratio 0.31 ). Non-synonymous changes hence constitute $55.1 \%$ of intraspecies polymorphism but only $38.5 \%$ of interspecies divergence, suggesting that approximately one-third of observed amino acid variation within sequenced $P$. falciparum isolates is deleterious and would naturally undergo purifying selection over a longer period.

\section{Conservation across the Plasmodium genus}

Study of conservation across the Plasmodium genus was undertaken using orthologous protein sequences from the rodent parasite $P$. chabaudi, as genome sequencing of $P$. chabaudi was at a more advanced stage at the time of the studies than other available rodent species. P. falciparum (3D7) protein sequences were compared with $P$. chabaudi; an average score for all hominid malaria variants would strictly be more accurate, although this would only influence approximately $1 \%$ of 
Table 1 Reference set of genes

\begin{tabular}{|c|c|c|c|c|c|}
\hline$P$. falciparum gene & Other identifier & Product & Pf amino acids & P. chabaudi gene & Pc amino acids \\
\hline \multicolumn{6}{|l|}{ ATPases } \\
\hline PFA0300c & MAL1P1.52 & Vacuolar ATPase-coupled proton transport & 383 & PCHAS_020560 & 383 \\
\hline PFC0840w & PfATPase7 & Phospholipid transporting ATPase & 1864 & PCHAS_080610 & 1773 \\
\hline PFE0195w & PfATPase3 & Cation transporting ATPase & 2393 & PCHAS_110330 & 1904 \\
\hline PF07_0047 & None & Cell-division cycle ATPase & 1229 & PCHAS_122230 & 1106 \\
\hline PF08_0113 & None & Vacuolar proton transporting ATPase & 1053 & PCHAS_122440 & 957 \\
\hline PFI0240c & None & $\mathrm{Cu}^{2+}$ - transporting ATPase & 2563 & PCHAS_041740 & 2128 \\
\hline PFL0590C & PfATPase4 & Non-SERCA type $\mathrm{Ca}^{2+}$-transporting ATPase & 1208 & PCHAS_020540 & 1468 \\
\hline PFL1125w & MAL12P1.225 & Phospholipid transporting ATPase & 1618 & PCHAS_144030 & 1601 \\
\hline \multicolumn{6}{|l|}{ Transporters } \\
\hline PFB0210c & PfHT1 & Hexose transporter & 504 & PCHAS_030470 & 505 \\
\hline PFB0465C & PF02_0097 & Monocarboxylate transporter & 457 & PCHAS_030940 & 456 \\
\hline PFE1185w & MAL5P1.237 & Metal transporter & 684 & PCHAS_123900 & 704 \\
\hline PFF0450c & MAL6P1.94 & $\mathrm{Zn}^{2+}$ or $\mathrm{Fe}^{2+}$ transporter & 361 & PCHAS_010830 & 338 \\
\hline PFF0170w & MAL6P1.38 & Calcium antiporter & 441 & PCHAS_010300 & 440 \\
\hline PFF1430c & MAL6P1.133 & Amino acid transporter & 606 & PCHAS_112780 & 617 \\
\hline PFI1295C & None & Monocarboxylate transporter & 529 & PCHAS_082700 & 507 \\
\hline PF11_0210 & None & $\mathrm{Mg}^{2+}, \mathrm{Co}^{2+} \& \mathrm{Ni}^{2+}$ channel & 529 & PCHAS_091640 & 435 \\
\hline PF11_0338 & PfAQP & Aquaglyceroporin & 258 & PCHAS_093040 & 258 \\
\hline MAL13P1.23 & None & CorA-like $\mathrm{Mg}^{2+}$ transporter & 468 & PCHAS_140460 & 491 \\
\hline PF13_0252 & PfNT1 & Nucleoside transporter & 422 & PCHAS_136470 & 414 \\
\hline PF14_0679 & None & Inorganic anion antiporter & 664 & PCHAS_133900 & 700 \\
\hline \multicolumn{6}{|l|}{ Glycolytic } \\
\hline PFF1155w & MAL6P1.189 & Hexokinase & 493 & PCHAS_112240 & 494 \\
\hline PF14_0341 & None & Glucose-6-phosphate isomerase & 579 & PCHAS_100870 & 578 \\
\hline PFI0755C & None & 6-Phosphofructokinase & 1418 & PCHAS_081620 & 1306 \\
\hline PF14_0425 & None & Fructose-bisphosphate aldolase & 369 & PCHAS_131180 & 369 \\
\hline PF14_0378 & None & Triosephosphate isomerase & 248 & PCHAS_130700 & 248 \\
\hline PFI1105W & PGK & Phosphoglycerate kinase & 416 & PCHAS_082320 & 416 \\
\hline PF11_0208 & None & Phosphoglycerate mutase & 250 & PCHAS_091620 & 250 \\
\hline PF10_0155 & None & Enolase & 446 & PCHAS_121500 & 446 \\
\hline PFF1300w & MAL6P1.160 & Pyruvate kinase & 511 & PCHAS_112510 & 511 \\
\hline PF13_0141 & PfLDH & L-lactate dehydrogenase & 316 & PCHAS_134470 & 316 \\
\hline \multicolumn{6}{|l|}{ DNA/RNA } \\
\hline PFB0730w & PF02_0151 & DEAD/DEAH box helicase & 1997 & PCHAS_031480 & 1404 \\
\hline PFC0805w & MAL3P6.20 & DNA-directed RNA polymerase ॥ & 2457 & PCHAS_080680 & 2307 \\
\hline PFE0465c & MAL5P1.95 & RNA polymerase I & 2914 & PCHAS_110870 & 2570 \\
\hline PFE0715w & MAL5P1.144 & Asparagine-tRNA ligase & 1128 & PCHAS_111360 & 1084 \\
\hline PFF1095w & MAL6P1.201 & Leucyl tRNA synthase & 1447 & PCHAS_112120 & 1251 \\
\hline MAL7P1.145 & None & Mismatch repair protein pms1 & 1330 & PCHAS_020880 & 1094 \\
\hline PF13_0251 & None & DNA topoisomerase III & 710 & PCHAS_136460 & 676 \\
\hline PF14_0234 & None & DNA-directed DNA polymerase & 1236 & PCHAS_101890 & 989 \\
\hline PF14_0316 & None & DNA topoisomerase II & 1472 & PCHAS_101120 & 1460 \\
\hline PF14_0695 & None & DNA-directed RNA polymerase & 861 & PCHAS_134050 & 796 \\
\hline
\end{tabular}

residues. The mean level of protein conservation per gene ranged widely across the reference set of 40 housekeeping genes (mean +4.88 to -0.47 based on the BLOSUM62 matrix). It was also noted that overall $20.1 \%$ of $P$. falciparum residues were non-aligned, compared to $13.3 \%$ for P. chabaudi, consistent with expansion of non-aligned sequence in the hominid malaria lineage since the last common ancestor of these species.

\section{Correlation between short and long-term conservation}

At the whole-gene level the $\mathrm{dN} / \mathrm{dS}$ ratio for $P$. falciparum - P. reichenowi divergence strongly correlated 
with the mean cross-genus conservation score (Figure $\left.1 \mathrm{a}, \mathrm{r}^{2}=0.69, \mathrm{p}<0.0001\right)$; as expected $\mathrm{dS}$ showed no such relationship. For polymorphism within $P$. falciparum (where interpretation of $\mathrm{dN} / \mathrm{dS}$ is less straightforward [20]), non-significant trends of the same form were seen (Figure 1b). Gene function also appeared to be associated with the degree of purifying selection, with glycolytic enzymes showing lower $\mathrm{dN} / \mathrm{dS}$ values than the other groups (Figure 1c) consistent with previous work [18]. We compared our $\mathrm{dN} / \mathrm{dS}$ scores for P. falciparum/ reichenowi divergence (Nei-Gojobori method with JukesCantor correction) with those previously reported for the same 40 genes using maximum likelihood for calculation of $\mathrm{dN} / \mathrm{dS}$ [18]. The two sets of results were well correlated (Spearman $r=0.96$ ) indicating that in relative terms $\mathrm{dN} / \mathrm{dS}$ is very similar for the differing methods; it also confirms that the fixed difference datasets between the two studies are highly comparable. The slope of the line of correlation between our results and those of Jeffares et al. [18] was 0.81 suggesting that the Nei-
Gojobori analysis overestimates $\mathrm{dN} / \mathrm{dS}$ to a small degree compared to PAML.

A stratified analysis was undertaken in which each amino acid residue was assigned to one of four levels of cross-genus evolutionary conservation according to $P$. falciparum - P. chabaudi CLUSTALW alignment. Residues were defined as non-aligned, non-conserved ( -4 to $-1)$, semi-conserved $(0$ to +3$)$ and identical $(+4$ and above) on the basis of the BLOSUM62 matrix. Synonymous substitution rates within the hominid malaria clade were similar across all levels of conservation (Figure 2a) but non-synonymous substitution rates were strongly influenced by long-term evolutionary context (Figure $2 b$ ). The $d N / d S$ ratio for divergence was approximately 20 -fold higher at non-aligning residues (0.64) compared to residues identical across the genus (0.034; Table 2). Chi-squared testing comparing divergence with polymorphism (McDonald-Kreitman test) within each conservation stratum showed that strong purifying selection was largely confined to residues
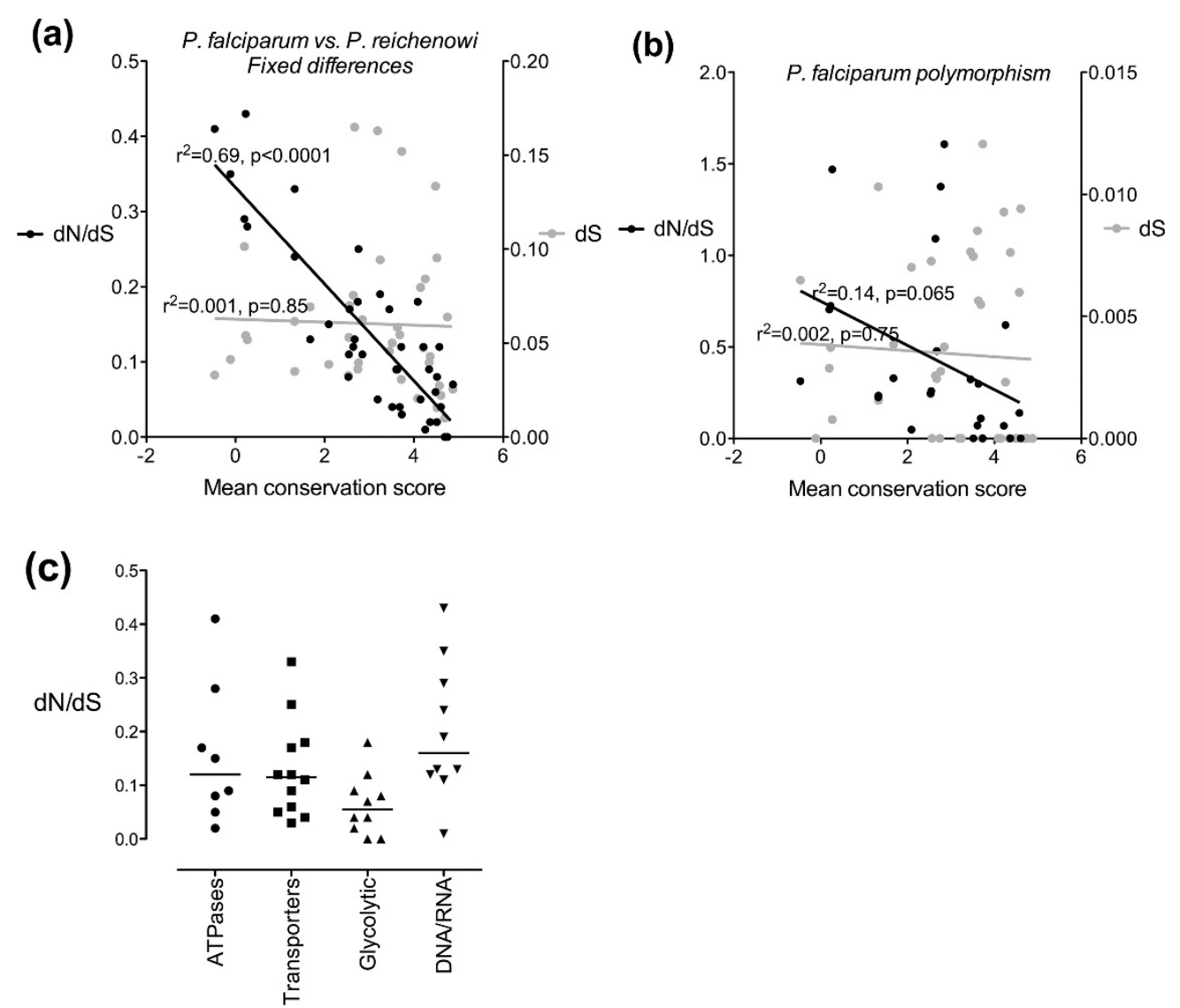

Figure 1 Hominid malaria clade divergence and conservation across the Plasmodium genus. For the forty individual genes of the reference set, $\mathrm{dN} / \mathrm{d} S$ and $\mathrm{dS}$ are plotted against mean conservation score for each gene. (a) Fixed differences between $P$. falciparum and $P$. reichenowi. (b) Polymorphisms within $P$. falciparum. (c) dN/dS ratios for fixed differences between $P$. falciparum and $P$. reichenowi according to functional group. 
(a)

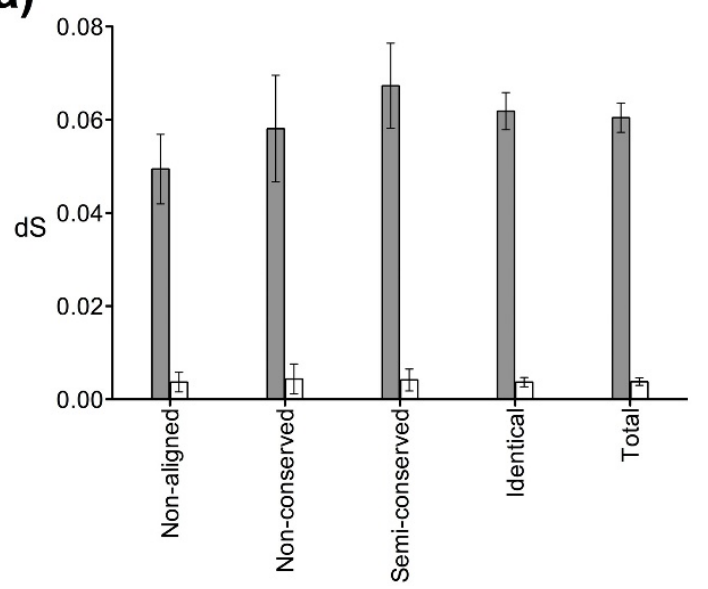

(b)

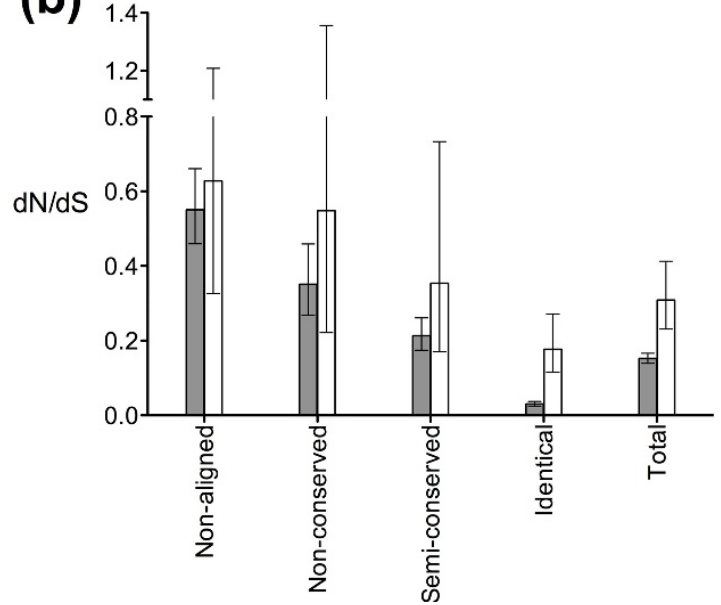

Figure 2 Mutation rates within the hominid malaria clade stratified by conservation level across the Plasmodium genus. (a) Synonymous substitution rates. (b) dN/dS ratios. Data are based on 40 reference genes. Fixed differences between $P$. falciparum and $P$. reichenowi are indicated by filled grey bars; polymorphism within $P$. falciparum is indicated by empty bars. Error bars represent $95 \%$ confidence intervals. Conservation levels were based on BLOSUM62 score at individual amino acids in P. falciparum - P. chabaudi alignments; identical (+4 and above), semi-conserved (0 to +3$)$, non-conserved (-4 to -1) and non-aligned.

identical across the genus (Table 2), with minimal evidence for purifying selection in non-aligned sequence regions.

\section{Relationship between evolutionary conservation,} hydrophilicity and informational complexity

Given the lack of a gold-standard informatic approach to defining non-globular regions, the relationship between conservation and non-globularity was explored via one purely structural marker of non-globularity (Kyte-Doolittle hydrophilicity) as well as a purely informational one (low-complexity regions defined by the SEG algorithm). These studies were undertaken in the context of an approach to cross-genus conservation measurement designed for high throughput use, involving a sliding window of 9 amino acid residues.

Decreasing cross-genus conservation was linked to both a shift to unusually high hydrophilicity scores, with a clear inflexion point present between conservation scores of 2 and 3 (Figure 3), and a reduction in strength of negative selection within the hominid malaria clade (Figure 4). A minority (31\%) of sequence with conservation score less than 2.5 was responsible for $77 \%$ of nonsynonymous differences between $P$. falciparum and $P$. reichenowi, including $87 \%$ of radical substitutions (Figure 4c). Low-complexity regions defined by the SEG

Table 2 Divergence and polymorphism in reference genes assessed by McDonald-Kreitman test, stratified by level of cross-genus conservation

\begin{tabular}{|c|c|c|c|c|c|c|c|}
\hline Conservation level & $\mathrm{dN} / \mathrm{dS}$ & Adjusted dN/dS & & Synonymous & Non-synonymous & Chi-squared & Neutrality Index \\
\hline \multirow[t]{2}{*}{ Identical } & 0.030 & 0.034 & $\mathrm{D}$ & 839 & 101 & $8.3 \times 10^{-15}$ & 5.6 \\
\hline & & & $\mathrm{P}$ & 52 & 35 & & \\
\hline \multirow[t]{2}{*}{ Semi-conserved } & 0.21 & 0.24 & $\mathrm{D}$ & 186 & 174 & 0.22 & 1.6 \\
\hline & & & $\mathrm{P}$ & 12 & 18 & & \\
\hline \multirow[t]{2}{*}{ Non-conserved } & 0.35 & 0.39 & $\mathrm{D}$ & 90 & 118 & 0.38 & 1.5 \\
\hline & & & $P$ & 7 & 14 & & \\
\hline \multirow[t]{2}{*}{ Non-aligned } & 0.55 & 0.64 & $\mathrm{D}$ & 155 & 402 & 0.74 & 1.1 \\
\hline & & & $\mathrm{P}$ & 12 & 35 & & \\
\hline \multirow[t]{2}{*}{ Total } & 0.15 & 0.17 & $\mathrm{D}$ & 1270 & 795 & $9.5 \times 10^{-6}$ & 2.0 \\
\hline & & & $\mathrm{P}$ & 83 & 102 & & \\
\hline
\end{tabular}

$\mathrm{dN} / \mathrm{dS}$ ratios refer to $P$. falciparum /P. reichenowi divergence. Conservation levels were based on BLOSUM62 score in $P$. falciparum - $P$. chabaudi alignments; identical ( +4 and above), semi-conserved $(0$ to +3$)$, non-conserved ( -4 to -1$)$ and non-aligned. Adjusted dN/dS ratios were derived based on the transition: transversion ratio measured at 4-fold degenerate sites (see Table 4). D = divergent mutations, $\mathrm{P}=$ polymorphisms. Chi-squared and Neutrality Index are the outputs of the McDonald-Kreitman test; neutrality index indicates the extent to which the levels of variation depart from the expected in the neutral model with values greater than 1 indicating an excess of polymorphism and hence negative selection. 


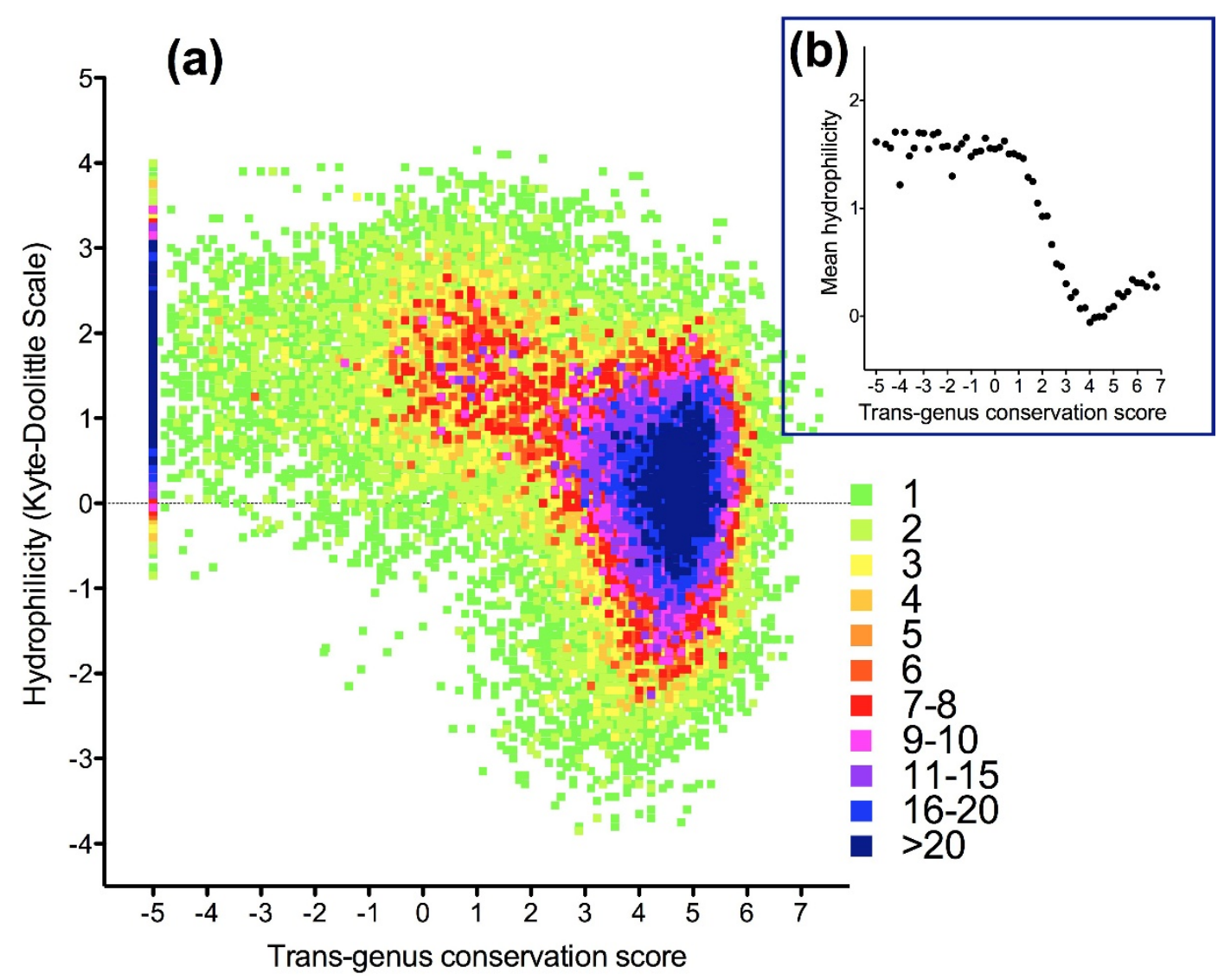

Figure $\mathbf{3}$ Density plot of conservation vs. hydrophilicity for amino acid residues of $\mathbf{4 0}$ reference genes. (a) Number of occurrences at each co-ordinate (using bins of 0.1 on both $\times$ and Y-axes). (b) Average hydrophilicity (conservation score bins of 0.2). Conservation levels in $P$. falciparum - P. chabaudi alignments were based on BLOSUM62 score using a sliding, overlapping window of 9 residues; hydrophilicity was based on the Kyte-Doolittle index (sliding, overlapping window of 14).

algorithm (default parameters) made up $11.9 \%$ of the sequence studied (missing many poorly conserved regions of sequence and including some highly conserved areas), and contained only $19.0 \%$ of non-synonymous differences between $P$. falciparum and $P$. reichenowi. Taken together these observations indicate that a measurement of cross-genus evolutionary conservation identifies highly hydrophilic sequences that show relaxed purifying selection in the short-term, features of non-globular domains, and that this method appears superior to an approach based purely on informational complexity.

\section{Chromosomal regions containing genes responsible for drug resistance in field isolates}

In order to test the utility of this approach for detecting functional variation in $P$. falciparum, we examined three chromosomal regions containing PfCRT, PfDHFR and PfDHPS, testing polymorphisms between two pairs of sensitive and resistant parasite isolates in each case. As observed with the reference genes, there were wide ranging levels of long-term conservation (Figure 5), and a similar shift to very high levels of hydrophilicity at conservation scores below 3 in all three cases (Figure 6). Indeed, the proportion of sequence falling below a conservation threshold of 2.5 was even greater than in the reference gene set $(56 \%$ vs. $31 \%$ ) indicating that at a genomic level non-globular domains may be responsible for an even higher proportion of non-synonymous polymorphism than in our reference genes. Consistent with this, amino acid variants in genes not involved in drug resistance fell almost exclusively in less conserved regions with 150 of 153 such amino acid variants below the 2.5 conservation threshold (Figure 5g, Chi-squared test for proportion of mutations vs. proportion of total sequence at each conservation level: $\left.\mathrm{p}=9 \times 10^{-23}\right)$. In contrast 22 amino acid variants within known drug-resistance genes were located in more conserved regions (Chisquared test for proportion of mutations vs. proportion of total sequence at each conservation level: $\mathrm{p}=$ $3.8 \times 10^{-7}$ ), with all mutations being located at 

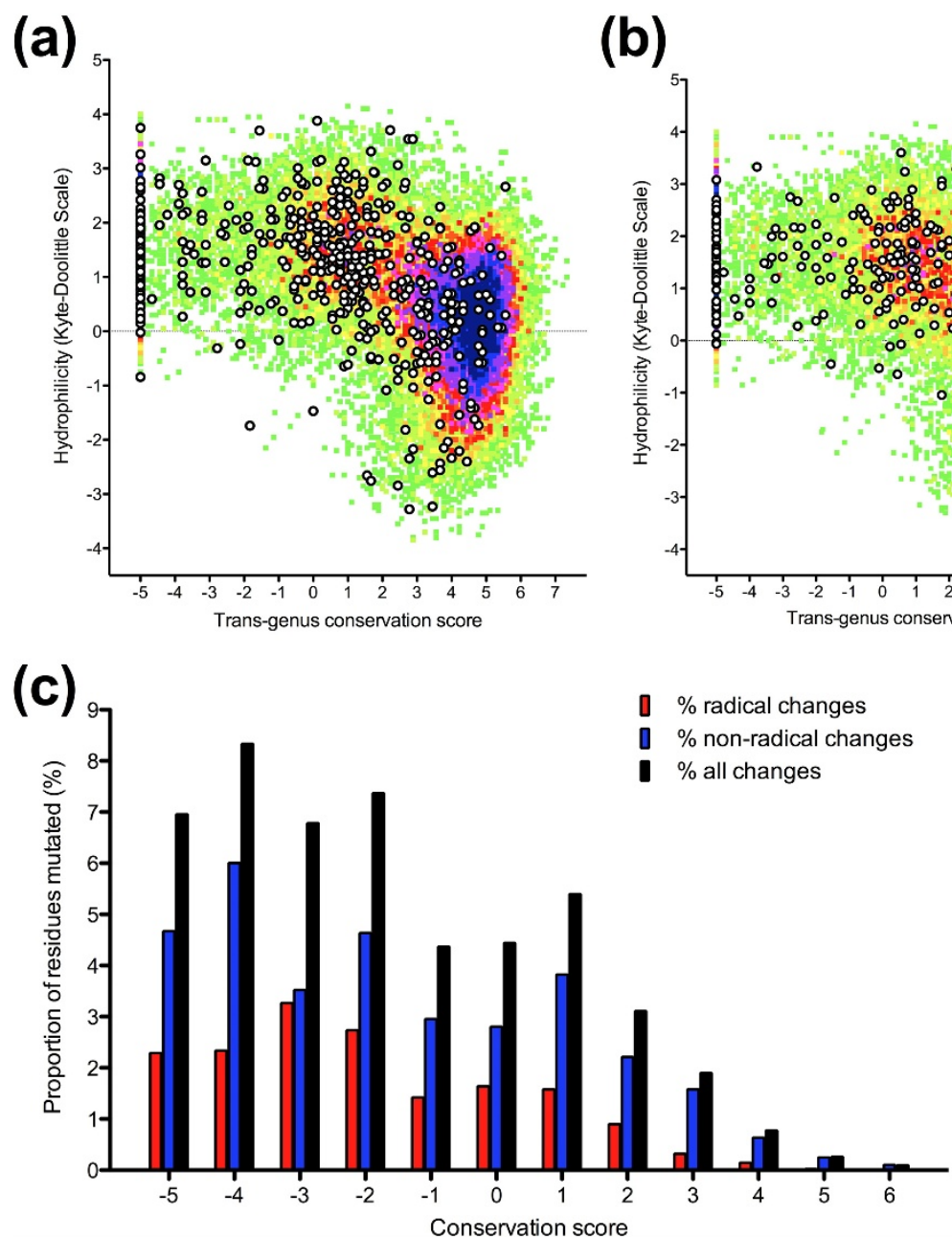

Figure 4 Conservation-hydrophilicity at sites of amino acid variants in $\mathbf{4 0}$ reference genes. (a) Conservative amino acid variants between P. falciparum and P. reichenowi. (b) Radical amino acid variants between P. falciparum and P. reichenowi. (c) Proportion of total sequence, conservative amino acid variants and radical amino acid variants according to conservation level (conservation score bins of 1.0). Conservation and hydrophilicity were derived as for Figure 3.

positions with relatively high conservation scores (> 3.0). Further there was no overlap in conservation scores between amino acid variants in the drug-resistance gene and those within other genes within any single alignment. These results indicate that the position of mutations within a long-term and measurable evolutionary landscape provides a robust signature that can aid identification of functionally important amino acid variants.

\section{Laboratory-selected drug resistance}

Fourteen amino acid variants associated with selection of atovaquone, azithromycin and spiroindolone resistance in vitro (involving mitochondrial, apicoplast and nuclear genomes respectively [21-23]) conformed to the same pattern (Figure 7). Combining these with field resistance mutations produced a set of 36 non-

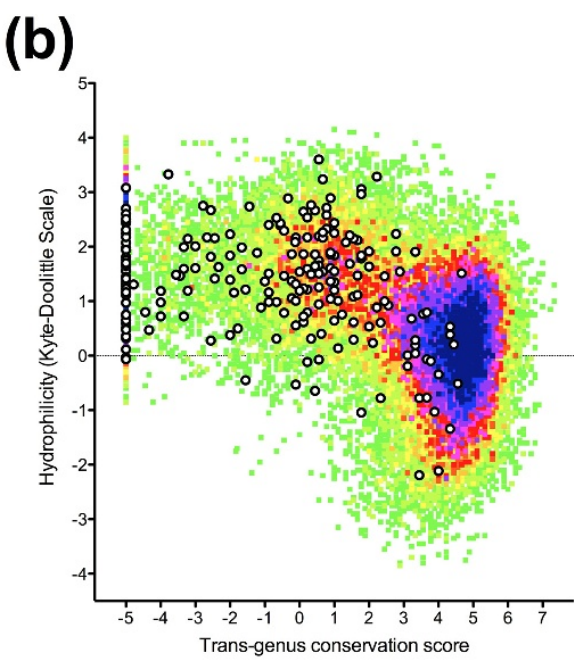

[. \% radical changes

$0 \%$ non-radical changes

- $\%$ all changes synonymous polymorphisms associated with drug resistance. Notably, among these mutations the nature of the amino acid variants itself (radical vs. conservative) provided no discriminatory value, indicating that it is primarily the location of the protein change that distinguishes functional adaptation.

\section{Population data from $P$. falciparum isolates}

Evolutionary analysis of long-term conservation is also relevant to population studies on large numbers of field samples since the neutral theory of evolution describes a strong relationship between selective pressure and allele frequency [24]. Sequences of PfSERCA, a postulated target of artemisinin, have been determined for thousands of isolates across the world (See Table 3 for data sources). Consistent with neutral evolution, maximum allele frequencies for amino acid variants in PfSERCA 


\section{(a)}

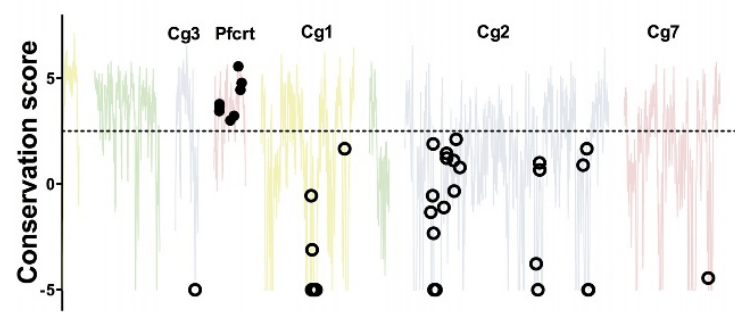

(b) CRT locus, HB3 v. 7 G8

(c)

DHFR locus, 3D7 v. Dd2

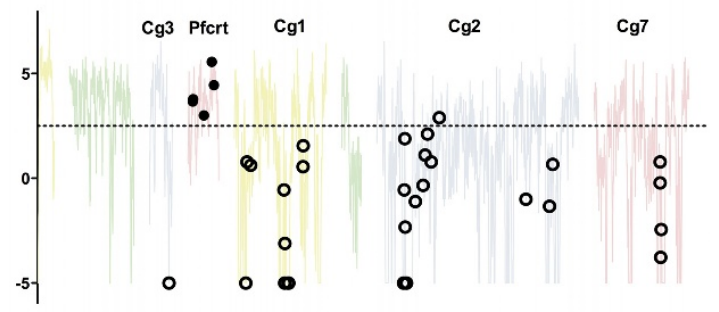

(d)
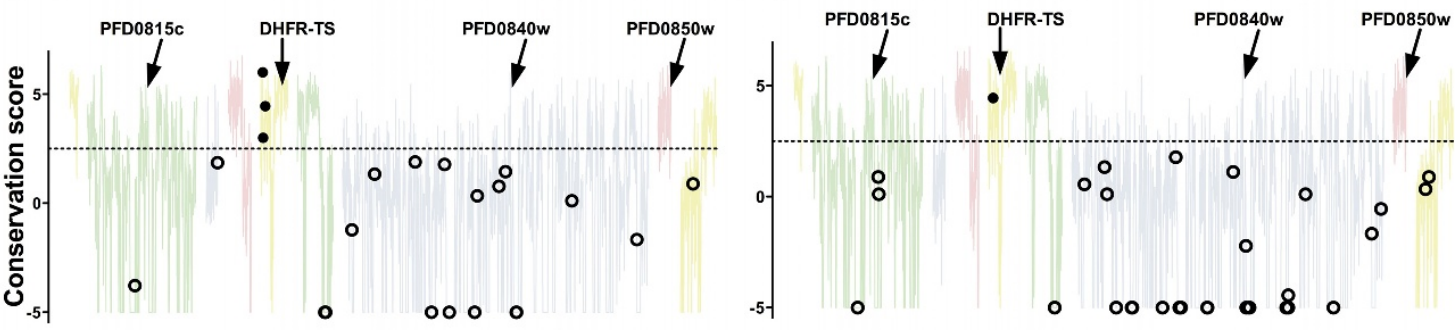

(e)

DHPS locus, HB3 v. Dd2

(f)

DHPS locus, HB3 v. K1
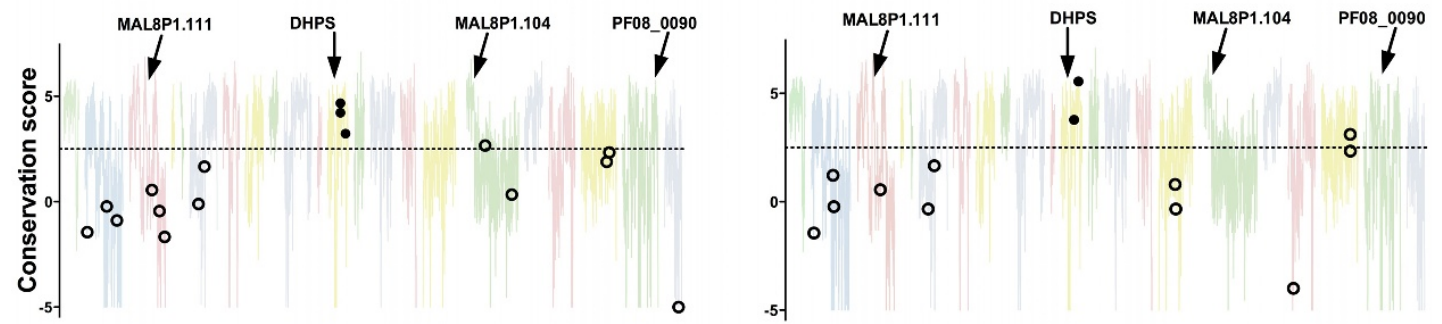

(g)

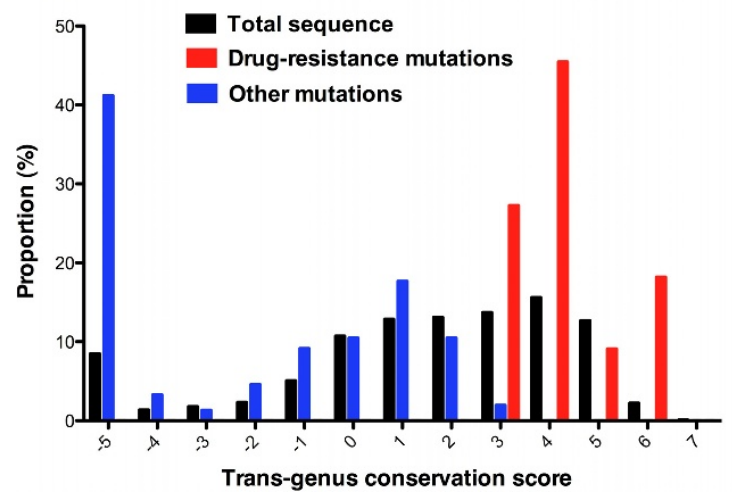

Figure 5 Relationship between Plasmodium genus conservation score and amino acid variation in $P$. falciparum drug-resistance regions. For each of three drug-resistance regions, two comparisons between resistant and sensitive isolates were made. (a, b) CRT resistance locus on chromosome 7. (c, d) DHFR resistance locus on chromosome 4. (e, f) DHPS locus on chromosome 8. Mutations in known drugresistance genes are shown as filled circles; other mutations are shown as open circles. A threshold conservation score of 2.5 is indicated by the dotted line. Only coding regions are displayed, with gene designations and colours used for orientation purposes only. (g) Proportion of total sequence, amino acid variation in drug-resistance genes and amino acid variation in other genes according to conservation level (based on a sliding window of 9 residues, with conservation scores shown within bins of 1.0). 

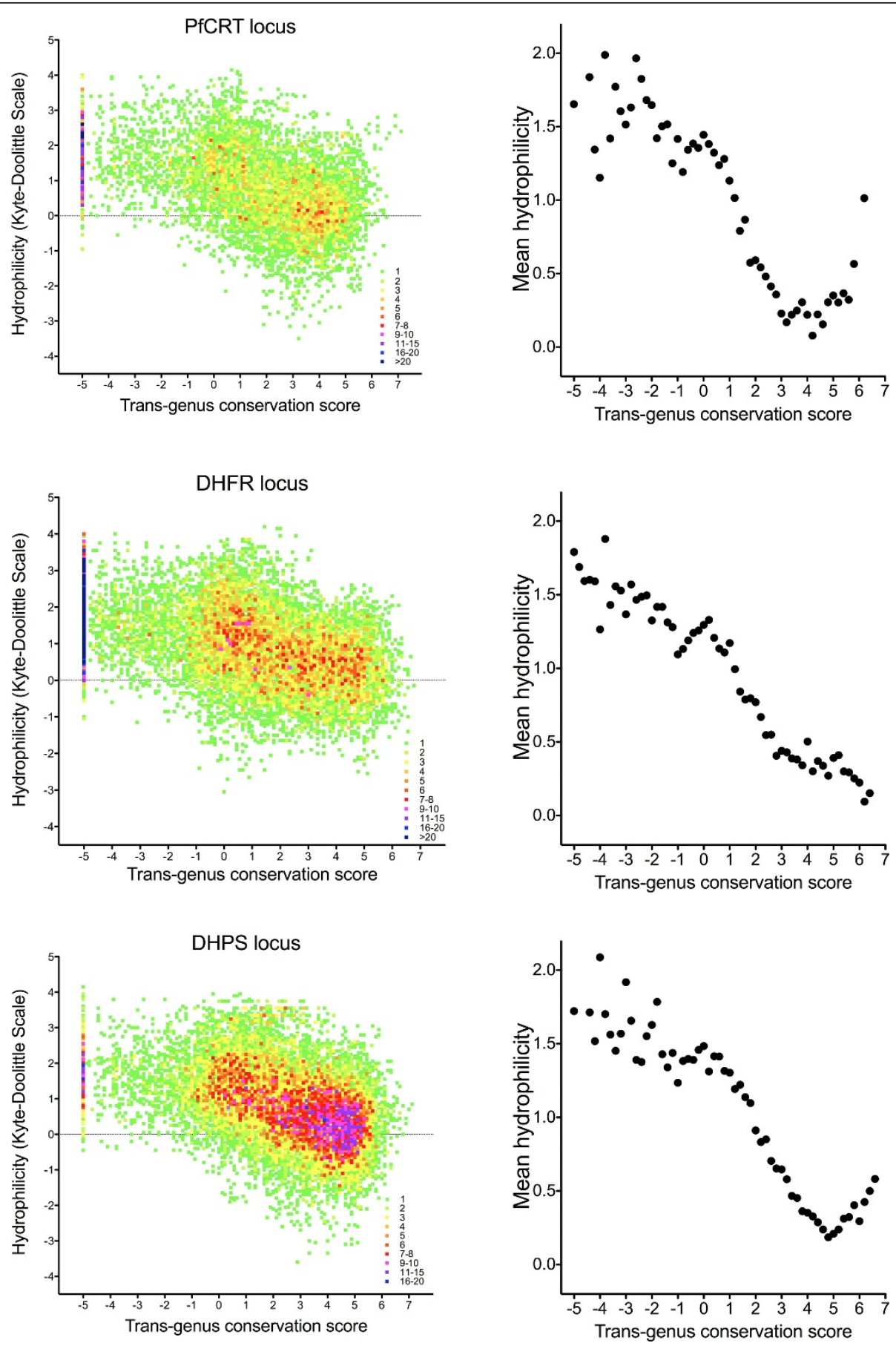

Figure 6 Density plot of conservation vs. hydrophilicity for 3 drug resistance regions. Left: Number of occurrences at each co-ordinate (using bins of 0.1 on both $\times$ and Y-axes). Right: Mean hydrophilicity by conservation score (bins of 0.2). Conservation and hydrophilicity are derived as for Figure 3.

were linked closely to cross-genus conservation level. All mutations reaching a prevalence of more than $25 \%$ were located in regions of low conservation (Figure 8a), matching the pattern of fixed differences between $P$. falciparum and $P$. reichenowi SERCAs. The opposite pattern was seen with amino acid variants associated with spiroindolone resistance in PfATPase4, which stand out distinctly against the flow of corresponding amino acid variants between $P$. falciparum and $P$. reichenowi ATPase4 sequences (Figure 8b). 


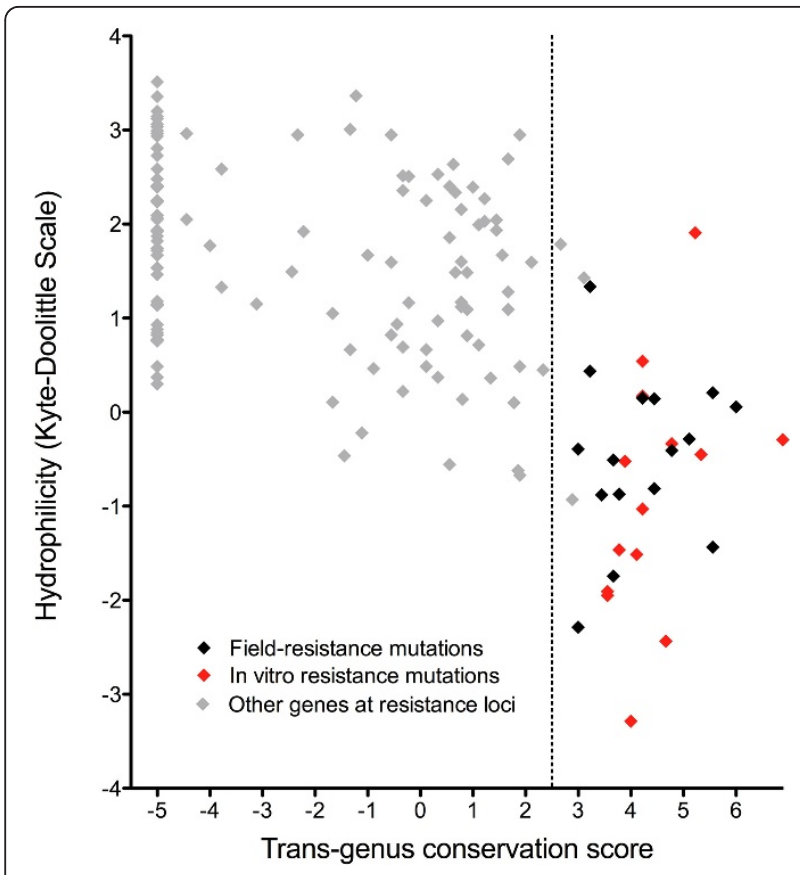

Figure 7 Conservation-hydrophilicity plot for amino acid variants associated with drug resistance or within drugresistance regions. All mutations shown to be involved in drug resistance by transfection (22 nSNPs in CRT, DHFR and DHPS) or drug pressure studies (14nSNPs in cytochrome b, rpl4 and PfATPase4) are shown along with variants in chromosomal regions around CRT, DHFR and DHPS (see Figure 5).

\section{Discussion}

Non-adaptive evolution in Plasmodium

We show that genes that maintain synteny and clearly defined orthologous relationships across the genus also contain poorly conserved domains that occupy approximately half of the total coding sequence when analysed at the chromosomal level. In other words, in Plasmodium species, negative (purifying) selective force is unusually chimeric in nature, being alternately strong and weak within the same gene. Plasmodium chabaudi has approximately two-thirds as much non-aligned sequence as $P$. falciparum, while other work on a genome-wide scale indicates that $P$. vivax has approximately $40 \%$ [25]. This indicates that the phenomenon is genus-wide, being particularly marked in the hominid malaria clade. The reason why internal proteins mediating core biological functions possess such widespread areas of nonglobular domain experiencing minimal purifying selection remains obscure but our data are certainly consistent with these sequences representing a downstream consequence of genetic processes $[13,26]$ such as replication slippage and unequal crossing over [27]. The $\mathrm{dN} /$ $\mathrm{dS}$ ratio of 0.64 in non-aligned regions suggests that these sequences are under very weak negative selective
Table 3 Maximum field allele frequencies for nonsynonymous mutations in PfSERCA (PFA0310c, PfATP6)

\begin{tabular}{llll}
\hline Mutation & Frequency (\%) & Location & Reference \\
\hline R37K & 100 & Venezuela & {$[54]$} \\
K67R & 3 & Ghana & {$[54]$} \\
K88E & 1 & Tanzania & {$[54]$} \\
I89T & 38 & Philippines & {$[54]$} \\
S176N & 3 & Malawi & {$[54]$} \\
V229I & $<1$ & Zanzibar & {$[55]$} \\
I230T & 3 & Iran & {$[54]$} \\
H243Y & 5 & Malawi & {$[54]$} \\
A338V & 1 & Tanzania & {$[54]$} \\
L402V & 28 & Brazil & {$[56]$} \\
D405N & 1 & Tanzania & {$[54]$} \\
E431K & 58 & Ethiopia & {$[57]$}
\end{tabular}

E432K

D436N 3

A438D 18

N462D $\quad 10$

N463S 3

464 del 2

N465S $\quad 16$

S466N 35

S5291

K561N

N569K

G585D

T602I

L610I

K611N

N612D

A621D

A623E

A630S

G632E

T635K

E637G

G639D

S641G

E643Q

N644I

K649E

L650W

T657I

N683K

1723V

H747Y

S769N

K771A

K776N

K783E

G805E

R809G

844 del
Cameroon

Tanzania

Vanuatu

Venezuela

Vietnam

[59]

Cambodia

Thailand

Peru

Tanzania

Niger

Zanzibar

Zanzibar

Zanzibar

Tanzania

Zanzibar

Zanzibar

Zanzibar

Ethiopia

Brazil

Malawi

Madagascar

Zanzibar

Venezuela

Zanzibar

Zanzibar

Zanzibar

Zanzibar

Bangladesh

Malawi

Bangladesh

Tanzania

Madagascar

Ethiopia

Angola

Angola

Tanzania

Malawi

Zanzibar

Peru
[54] 
Table 3 Maximum field allele frequencies for non-synonymous mutations in PfSERCA (PFA0310c, PfATP6) (Continued)

\begin{tabular}{llll}
\hline D845N & 3 & Tanzania & {$[54]$} \\
E847K & 2 & Thailand & {$[1]$} \\
T857S & 1 & Tanzania & {$[54]$} \\
A1115G & 4 & Papua New Guinea & {$[54]$} \\
V1169I & 24 & Brazil & {$[54]$} \\
S1187T & 3 & Ghana & {$[54]$} \\
D1228E & 3 & Ghana & {$[54]$} \\
\hline
\end{tabular}

3D7 sequence was used as reference. Only studies where alleles were determined for at least ten samples were included. Samples with mixed infections were included in each numerator.

pressure, with purifying selection perhaps acting only to maintain non-globular structure.

\section{Applications}

Improved understanding of these issues has major implications for the study of all Plasmodium biology that relates to evolution. The findings are most immediately relevant to the goal of understanding molecular mechanisms of drug resistance, since this represents a classical example of evolution in action. As predicted, we were able to show that mutations selected by drug pressure in the field or laboratory are located in conserved protein sequences that have remained largely unchanged for millions of years (being conserved across the Plasmodium genus) by virtue of their functional importance, as already noted by other authors [22,28-30]. What has not been considered is that the gradient in purifying selective force across the genus is strong enough to allow drug-resistance mutations to be discriminated accurately from those that are likely to non-adaptive in nature. Prediction of the functional consequences of mutations based on long-term evolutionary conservation has been described in the context of human genetic studies [31-33] but there is even greater scope for this approach to assist studies in P. falciparum, where the contribution of non-adaptive change appears to be log-orders of magnitude higher.

The potential for non-adaptive evolution to confound studies of genotype-phenotype relationships is clear in several areas. Candidate gene surveys based on sequencing of field isolates, where few or no phenotypic data are available, provide an obvious example; the majority of polymorphisms found in PfSERCA are seen to be located in poorly conserved regions, including all those reaching frequencies of more than $25 \%$ in field isolates. This finding indicates that polymorphism in this gene is dominated by non-adaptive evolution, and the temptation to invoke positive selection [34] should be avoided. Use of $\mathrm{dN} / \mathrm{dS}$ to infer positive selection in whole genome analyses of $P$. vivax [35] may also be prone to the
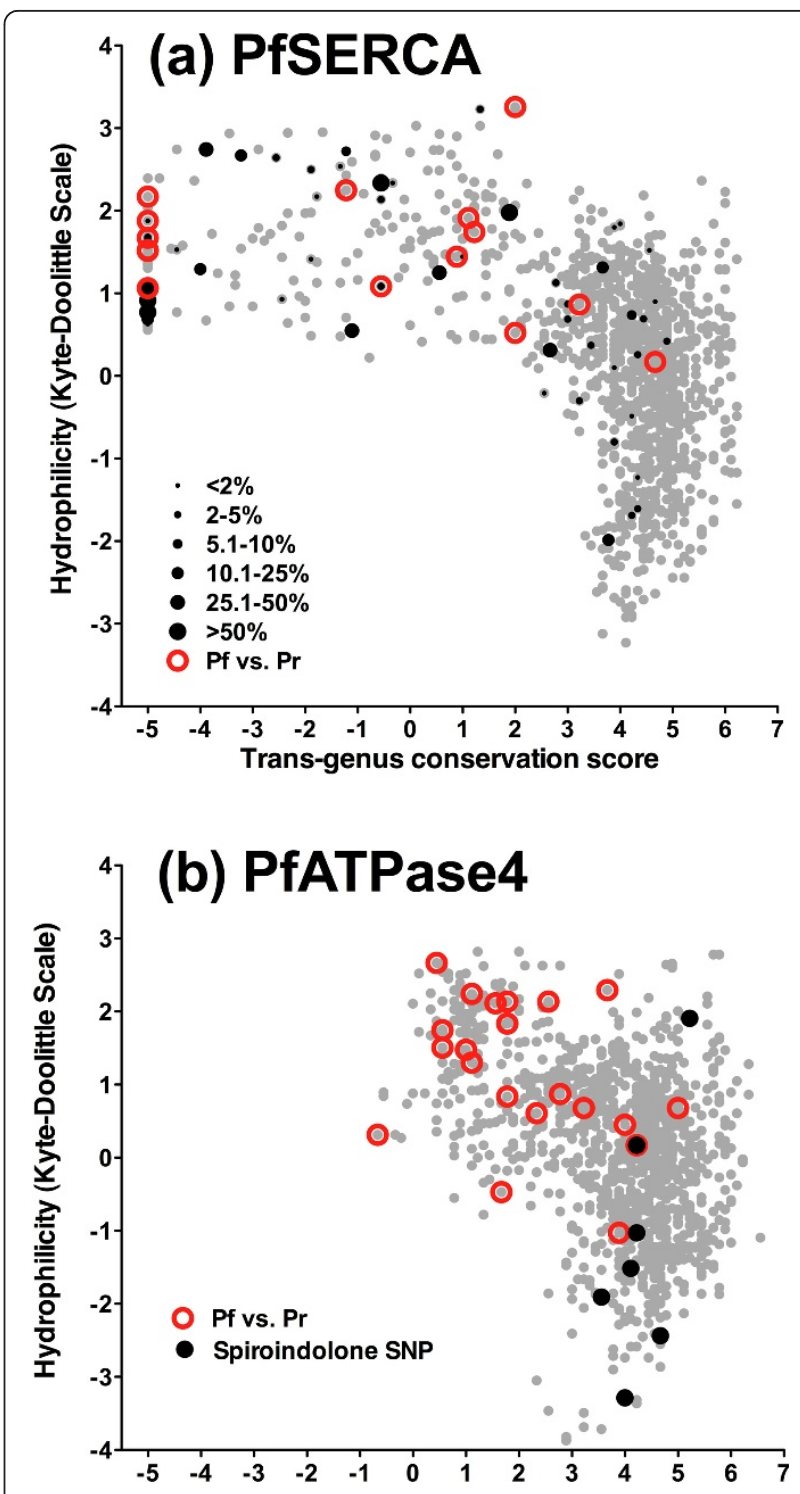

Figure 8 Conservation-hydrophilicity plots and singlenucleotide changes in the hominid malaria clade in calciumATPase genes. (a) PfSERCA (PFA0310c) showing amino acid variants between $P$. falciparum and $P$. reichenowi and field amino acid variants (see Table 3); symbol size indicates maximum allele frequency on a countrywide basis. (b) PfATPase4 (PFL0590c), showing amino acid variants between $P$. falciparum and $P$. reichenowi as well as the mutations associated with spiroindolone selection (see text). Conservation and hydrophilicity are derived as for Figure 3.

same issue; although measures of $\mathrm{dN} / \mathrm{dS}$ across a gene tend to be conservative due to purifying selection, it is still likely on statistical grounds that across a large number of genes, a number of high $\mathrm{dN} / \mathrm{dS}$ ratios (greater than one) will be generated simply by the action of nonadaptive evolution.

Understanding of the degree to which non-adaptive evolution occurs is also relevant to the identification of 
drug-resistance genes in a chromosomal context. In our analyses of regions known to contain drug-resistance genes, application of evolutionary conservation added considerable specificity with more than $95 \%$ of mutations outside drug-resistance genes falling into poorly conserved sequence. Nevertheless the accuracy of the evolutionary approach as it stands is unlikely to be sufficient for its use in isolation, but rather as a method for pinpointing polymorphisms within regions identified by other means, particularly genome-wide association studies using population genetic tests $[6,36]$. Genetic cross experiments are also a robust starting point; for example, the complex polymorphisms in the $c g 1$ and $c g 2$ genes seen at the chloroquine resistance locus identified by the cross of HB3 and DD2 [37] would be defined as being of low priority for further study by the approach we describe. Further work is in progress to examine systematically the evolutionary properties of other regions already identified as being of phenotypic importance by experimental means [38], with the aim of prioritizing polymorphisms for more detailed studies.

\section{Wider relevance}

Awareness of the chimeric selection landscape of Plasmodium coding sequences is also relevant to the study of the history of Plasmodium species. A higher $\mathrm{dN} / \mathrm{dS}$ at the whole gene level for hominid parasites $P$. falciparum and $P$. reichenowi compared to rodent malaria parasites has been suggested to provide evidence for small population size during the $P$. falciparum-reichenowi divergence [39]. However, based on the set of forty reference genes we studied, hominid malaria proteins contain significantly more non-aligned sequence than do rodents, likely leading to higher $\mathrm{dN} / \mathrm{dS}$ ratios at the whole gene level. In fact in sequence regions conserved across the Plasmodium genus the average $\mathrm{dN} / \mathrm{dS}$ ratio for the $P$. falciparum-P. reichenowi divergence was 0.034 , indicating strong purifying selection and implying a historically large population size following the lateral transfer of $P$. falciparum to humans from bonobos [40] or gorillas [41].

\section{Conclusion}

The coding sequences of Plasmodium species exemplify the theories of neutral evolution [14,42] and the ensuing nearly neutral theory [15], operating on a grand scale that to our knowledge is unrivalled in genome biology. Failing to take into account the effect of this in any work that relates to evolution of coding sequence represents a missed opportunity to distinguish adaptive from non-adaptive polymorphism. For example neither genome-wide or candidate gene association studies into antimalarial resistance currently take into account the fact that most polymorphism is non-adaptive in nature.
The approach we describe takes advantage of protein sequence data, but does not require any knowledge of protein function, a major advantage since the elucidation of function for the majority of Plasmodium genes remains a distant goal. Application of this method on a genome-wide scale, where it can be integrated into DNA-based methods as well as candidate gene approaches, offers a powerful approach for future studies in the field of antimalarial resistance, as well as other areas of research that are linked to evolutionary biology in this important genus.

\section{Methods}

\section{Comparisons between $P$. falciparum and $P$. chabaudi orthologs}

The rodent malaria species Plasmodium chabaudi was used as comparator species given its status in terms of genome completion. Protein and DNA sequences (Plasmodb version: 2009.03.24) were obtained from Plasmodb.org. Forty orthologous pairs of sequences were chosen, fulfilling the following criteria; no known or hypothesised role in drug resistance or host interaction, syntenic relationship between P. falciparum and P. chabaudi and $>75 \%$ coverage in the P. reichenowi ortholog [18] (used for measurement of divergence within hominid malaria parasites). Since sexual-stage genes are released from purifying selection in asexual culture (experienced by several of the isolates under study) [43] genes with no evidence of asexual expression in transcriptomic surveys $[44,45]$ were also excluded. In order to reflect the types of genes which are implicated in drug resistance, as well as to obtain a range of conservation levels across this reference set, the reference genes consisted of ATPases (8), secondarily active transporters (12), glycolytic enzymes (10) and enzymes involved in DNA and RNA processing (10)(Table 1). The Plasmodb gene model for PfL0590c (PfATPase4) was found to be inconsistent with published data based on cDNA; the latter were used as coding sequence [23].

CLUSTALW alignments of orthologous protein sequences from $P$. falciparum and P. chabaudi were performed using the default settings of BioEdit. BLOSUM62 scores (reflecting conservation) were then calculated for each $P$. falciparum residue. Regions that could not be aligned between $P$. falciparum and $P$. chabaudi orthologs were defined as the gaps in BLASTP alignments of $P$. falciparum and $P$. chabaudi orthologs (BLOSUM62 matrix, gap penalties: existence 9, extension 2) A manual check of the protein alignment in BioEdit was also performed and on rare occasions where short alignments had been excluded by the BLASTP search these were retained. For residues where there was no aligned $P$. chabaudi residue, a conservation score of -5 was applied. Relatively small regions with no $P$. reichenowi coverage were also 
removed from analysis to ensure comparable denominators for inter- and intra-species comparison.

\section{Annotation of polymorphisms and fixed differences}

We analysed single-nucleotide polymorphisms (SNPs) derived from Plasmodb, based on available sequence for various $P$. falciparum strains from around the world generated by the Broad Institute [46], Wellcome Trust Sanger Institute [18] and NIH [47]. Fixed differences between $P$. falciparum 3D7 strain and P. reichenowi (Oscar strain) were also obtained from Plasmodb [18]. Radical amino acid substitutions were defined as those with BLOSUM62 matrix score $<0$.

The challenge of identifying single nucleotide changes within a sequence that is undergoing frequent insertiondeletion polymorphism has been described [48]. In addition, we noted that although complex polymorphisms were said to be excluded in publications, the Plasmodb lists of SNPs within $P$. falciparum and fixed differences between $P$. falciparum 3D7 strain and $P$. reichenowi sometimes contained repetitive mutations within tandem repeats (confirmed by Pustell protein matrix, MacVector) that were clearly part of complex indel polymorphisms and hence not genuine SNPs. These regions contributed $27.5 \%$ of all SNPs among P. falciparum isolates and 9.4\% of the interspecies divergence, and were excluded from both polymorphism and divergence analyses.

\section{Calculation of positions and transitions}

Calculation of synonymous and non-synonymous positions was undertaken for each $P$. falciparum ortholog using a standard substitution matrix (assuming equal mutation rates) with Jukes-Cantor correction [49]. Confidence intervals for $\mathrm{dS}$ were determined assuming a continuous distribution. Confidence intervals for $\mathrm{dN} / \mathrm{dS}$ were determined using the delta method. Transitional bias was determined by studying synonymous fixed differences between $P$. falciparum and $P$. reichenowi orthologs occurring at amino acids encoded by four codons. Consistent with previous measurements on a chromosomal scale [50], synonymous sites made up $20.1 \%$ of all sites within the reference genes (See Table 4) with 8.9\% of sites being 4-fold degenerate sites (nucleotide positions at which all mutations are synonymous). For synonymous differences at 4-fold degenerate sites, which we assume are selectively neutral, transitions made up $41.4 \%$ of changes and transversions $58.6 \%$, consistent with a moderate transitional bias that would produce falsely low $\mathrm{dN} / \mathrm{dS}$ ratios [51] (since transitional mutations are associated with degeneracy at many 2 -fold degenerate sites). Taking this factor into account led to upwards revision of $\mathrm{dN} / \mathrm{dS}$ ratios for divergence of between 12 and 16\% according to the level of conservation; the effect was greatest for non-aligned sequence where the adjusted $\mathrm{dN} / \mathrm{dS}$ ratio rose to 0.64 (Table 1 ).

\section{Studies of hydrophilicity and complexity}

Hydrophilicity scores were measured by the Kyte-Doolittle index (window $=14$ ). Low-complexity regions were defined using the SEG algorithm at its default parameters [52].

\section{Drug-resistance chromosomal regions}

P. chabaudi orthologs were again used to generate the conservation score. In the case of one gene (MAL8P1.111) there was no rodent malaria parasite ortholog as previously reported [53] and in consequence the syntenic $P$. vivax ortholog was used for comparison. For the single apicoplast gene rpl4 the partial $P$. chabaudi sequence PC103611.00.0 was available for generation of the crossgenus conservation score at sites of mutation. For all studies at drug-resistance regions a neighbourhood conservation score was used (averaging the individual conservation scores across a sliding, overlapping window of 9 residues). This allows for the possibility that drug-resistance mutations may occur at residues that have previously undergone conservative change within a wider area of conservation, thereby reducing stochastic loss of sensitivity. This also obviated the need for a specific step to identify non-aligned regions at genomic regions. Nonsynonymous SNPs (nSNPs) between sensitive and resistant parasites were studied at each locus, spanning the drugresistance gene in each case and extending outwards symmetrically until $10 \mathrm{nSNPs}$ outside the drug-resistance gene itself had been documented in at least one pairwise comparison. All residues known to be intrinsic to resistance

Table 4 Synonymous sites in reference set of genes

\begin{tabular}{|c|c|c|c|c|c|}
\hline Conservation level & All & 4-fold & Transitional sites & Transversional sites & Adjusted S \\
\hline Identical & $14127(20.8)$ & $6384(9.4)$ & $6389(9.4)$ & $1354(2.0)$ & 15537 \\
\hline Semi-conserved & $2889(19.1)$ & $1249(8.3)$ & $1319(8.7)$ & $321(2.1)$ & 3176 \\
\hline Non-conserved & $1609(21.5)$ & $811(10.9)$ & $672(9.0)$ & $126(1.7)$ & 1759 \\
\hline Non-aligned & $3240(17.7)$ & $1187(6.5)$ & $1819(10.0)$ & $234(1.3)$ & 3658 \\
\hline Total & $21866(20.1)$ & 9631 (8.9) & $10200(9.4)$ & $2036(1.9)$ & 24131 \\
\hline
\end{tabular}

Transitional sites refer to 2-fold synonymous codons by virtue of transitional substitution; transversional sites to 2-fold synonymous codons by virtue of transversional substitution. Numbers in parentheses indicate proportion (\%) of total positions. 
haplotypes, whether or not each individual residue has been shown to cause drug-resistance independently, were included. Chi-squared testing was undertaken testing whether the distribution of amino acid variants in terms of conservation level was the same as the distribution of total sequence, using 13 conservation levels (bins of 1), and hence 12 degrees of freedom. The test was performed first for drug-resistance genes and mutations, and then for the other genes and the mutations within them.

\section{Acknowledgements}

CW and KG were funded by an MRC Clinician Scientist Fellowship to CW. NW is a Wellcome Trust Principal Fellow. The authors thank Arjen Dondorp, Mallika Imwong, Olivo Miotto, Chris Newbold and Sue Lee for helpful discussions. No funding body had any role in study design, collection, analysis, and interpretation of data, the writing of the manuscript or the decision to submit the manuscript for publication.

\section{Author details}

'Wellcome Trust Mahidol University-Oxford Tropical Medicine Research Unit (MORU), 420/6 Rajwithi Road, Bangkok, 10400 Thailand. ${ }^{2}$ Centre for Infection, St. George's, University of London, Cranmer Terrace, London, UK SW17 ORE. ${ }^{3}$ Sanger Malaria Programme, Wellcome Trust Sanger Institute, Hinxton, Cambridge, UK CB10 1SA UK.

\section{Authors' contributions}

$\mathrm{CW}, \mathrm{KG}, \mathrm{LB}, \mathrm{ND}$ and NW conceived the study design. KG, IS and CW performed data acquisition, coding and analysis. KG and CW produced the first draft of the paper and all authors amended the manuscript and approved the final version.

\section{Authors' information}

CW, ND and NW are clinicians based at the Mahidol-Oxford Tropical Medicine Research Unit and are engaged in tackling the problem of multidrug resistant malaria in Southeast Asia.

\section{Competing interests}

The authors declare that they have no competing interests.

Received: 24 March 2011 Accepted: 14 September 2011

Published: 14 September 2011

\section{References}

1. Dondorp AM, Nosten F, Yi P, Das D, Phyo AP, Tarning J, Lwin KM, Ariey F, Hanpithakpong W, Lee SJ, Ringwald P, Silamut K, Imwong M, Chotivanich K, Lim P, Herdman T, An SS, Yeung S, Singhasivanon P, Day NP, Lindegardh N, Socheat $\mathrm{D}$, White $\mathrm{NJ}$ : Artemisinin resistance in Plasmodium falciparum malaria. N Engl I Med 2009, 361(5):455-467.

2. Baird JK: Resistance to therapies for infection by Plasmodium vivax. Clin Microbiol Rev 2009, 22(3):508-534.

3. Wellems TE, Panton L, Gluzman IY, do Rosario VE, Gwadz RW, WalkerJonah A, Krogstad DJ: Chloroquine resistance not linked to mdr-like genes in a Plasmodium falciparum cross. Nature 1990, 345(6272):253-255.

4. Fidock DA, Nomura T, Talley AK, Cooper RA, Dzekunov SM, Ferdig MT, Ursos LM, Sidhu AB, Naude B, Deitsch KW, Su XZ, Wootton JC, Roepe PD, Wellems TE: Mutations in the P. falciparum digestive vacuole transmembrane protein PfCRT and evidence for their role in chloroquine resistance. Mol Cell 2000, 6(4):861-871.

5. Sa JM, Twu O, Hayton K, Reyes S, Fay MP, Ringwald P, Wellems TE: Geographic patterns of Plasmodium falciparum drug resistance distinguished by differential responses to amodiaquine and chloroquine. Proc Natl Acad Sci USA 2009, 106(45):18883-18889.

6. Mu J, Myers RA, Jiang H, Liu S, Ricklefs S, Waisberg M, Chotivanich K, Wilairatana P, Krudsood S, White NJ, Udomsangpetch R, Cui L, Ho M, Ou F, Li H, Song J, Li G, Wang X, Seila S, Sokunthea S, Socheat D, Sturdevant DE, Porcella SF, Fairhurst RM, Wellems TE, Awadalla P, Su XZ: Plasmodium falciparum genome-wide scans for positive selection, recombination hot spots and resistance to antimalarial drugs. Nat Genet 2010, 42(3):268-271.

7. MalariaGEN: A global network for investigating the genomic epidemiology of malaria. Nature 2008, 456(7223):732-737.

8. Mu J, Ferdig MT, Feng X, Joy DA, Duan J, Furuya T, Subramanian G, Aravind L, Cooper RA, Wootton JC, Xiong M, Su XZ: Multiple transporters associated with malaria parasite responses to chloroquine and quinine. Mol Microbiol 2003, 49(4):977-989

9. Anderson TJ, Nair S, Qin H, Singlam S, Brockman A, Paiphun L, Nosten F: Are transporter genes other than the chloroquine resistance locus (pfcrt) and multidrug resistance gene (pfmdr) associated with antimalarial drug resistance? Antimicrob Agents Chemother 2005, 49(6):2180-2188.

10. Gardner MJ, Tettelin H, Carucci DJ, Cummings LM, Aravind L, Koonin EV, Shallom S, Mason T, Yu K, Fujii C, Pederson J, Shen K, Jing J, Aston C, Lai Z, Schwartz DC, Pertea M, Salzberg S, Zhou L, Sutton GG, Clayton R, White O, Smith HO, Fraser CM, Adams MD, Venter JC, Hoffman SL: Chromosome 2 sequence of the human malaria parasite Plasmodium falciparum. Science 1998, 282(5391):1126-1132.

11. Pizzi E, Frontali C: Low-complexity regions in Plasmodium falciparum proteins. Genome Res 2001, 11(2):218-229.

12. Brocchieri L: Low-complexity regions in Plasmodium proteins: in search of a function. Genome Res 2001, 11(2):195-197.

13. Xue HY, Forsdyke DR: Low-complexity segments in Plasmodium falciparum proteins are primarily nucleic acid level adaptations. $\mathrm{Mol}$ Biochem Parasitol 2003, 128(1):21-32.

14. Kimura M: Evolutionary rate at the molecular level. Nature 1968, 217(5129):624-626.

15. Ohta T: Slightly deleterious mutant substitutions in evolution. Nature 1973, 246(5428):96-98.

16. Hughes AL: Near neutrality: leading edge of the neutral theory of molecular evolution. Ann N Y Acad Sci 2008, 1133:162-179.

17. Koonin EV: Darwinian evolution in the light of genomics. Nucleic Acids Res 2009, 37(4):1011-1034.

18. Jeffares DC, Pain A, Berry A, Cox AV, Stalker J, Ingle CE, Thomas A, Quail MA Siebenthall K, Uhlemann AC, Kyes S, Krishna S, Newbold C, Dermitzakis ET, Berriman M: Genome variation and evolution of the malaria parasite Plasmodium falciparum. Nat Genet 2007, 39(1):120-125.

19. Rich SM, Leendertz FH, Xu G, LeBreton M, Djoko CF, Aminake MN, Takang EE, Diffo JL, Pike BL, Rosenthal BM, Formenty P, Boesch C, Ayala FJ, Wolfe ND: The origin of malignant malaria. Proc Natl Acad Sci USA 2009, 106(35):14902-14907.

20. Kryazhimskiy S, Plotkin JB: The population genetics of dN/dS. PLoS Genet 2008, 4(12):e1000304.

21. Korsinczky M, Chen N, Kotecka B, Saul A, Rieckmann K, Cheng Q: Mutations in Plasmodium falciparum cytochrome $b$ that are associated with atovaquone resistance are located at a putative drug-binding site. Antimicrob Agents Chemother 2000, 44(8):2100-2108.

22. Sidhu AB, Sun Q, Nkrumah $L$, Dunne MW, Sacchettini JC, Fidock DA: In vitro efficacy, resistance selection, and structural modeling studies implicate the malarial parasite apicoplast as the target of azithromycin. $J$ Biol Chem 2007, 282(4):2494-2504.

23. Rottmann M, McNamara C, Yeung BK, Lee MC, Zou B, Russell B, Seitz P, Plouffe DM, Dharia NV, Tan J, Cohen SB, Spencer KR, Gonzalez-Paez GE, Lakshminarayana SB, Goh A, Suwanarusk R, Jegla T, Schmitt EK, Beck HP, Brun R, Nosten F, Renia L, Dartois V, Keller TH, Fidock DA, Winzeler EA, Diagana TT: Spiroindolones, a potent compound class for the treatment of malaria. Science 2010, 329(5996):1175-1180.

24. Kimura M: Average time until fixation of a mutant allele in a finite population under continued mutation pressure: Studies by analytical, numerical, and pseudo-sampling methods. Proc Natl Acad Sci USA 1980, 77(1):522-526

25. Carlton JM, Adams JH, Silva JC, Bidwell SL, Lorenzi H, Caler E, Crabtree J, Angiuoli SV, Merino EF, Amedeo P, Cheng Q, Coulson RM, Crabb BS, Del Portillo HA, Essien K, Feldblyum TV, Fernandez-Becerra C, Gilson PR, Gueye AH, Guo X, Kang'a S, Kooij TW, Korsinczky M, Meyer EV, Nene V, Paulsen I, White O, Ralph SA, Ren Q, Sargeant TJ, et al: Comparative genomics of the neglected human malaria parasite Plasmodium vivax. Nature 2008, 455(7214):757-763.

26. DePristo MA, Zilversmit MM, Hartl DL: On the abundance, amino acid composition, and evolutionary dynamics of low-complexity regions in proteins. Gene 2006, 378:19-30. 
27. Zilversmit MM, Volkman SK, Depristo MA, Wirth DF, Awadalla P, Hartl DL Low-Complexity Regions in Plasmodium falciparum: Missing Links in the Evolution of an Extreme Genome. Mol Biol Evol 2010.

28. Nomura T, Carlton JM, Baird JK, del Portillo HA, Fryauff DJ, Rathore D, Fidock DA, Su X, Collins WE, McCutchan TF, Wootton JC, Wellems TE: Evidence for different mechanisms of chloroquine resistance in 2 Plasmodium species that cause human malaria. J Infect Dis 2001, 183(11):1653-1661.

29. Cowman AF, Morry MJ, Biggs BA, Cross GA, Foote SJ: Amino acid changes linked to pyrimethamine resistance in the dihydrofolate reductasethymidylate synthase gene of Plasmodium falciparum. Proc Natl Acad Sci USA 1988, 85(23):9109-9113.

30. Triglia T, Cowman AF: Primary structure and expression of the dihydropteroate synthetase gene of Plasmodium falciparum. Proc Natl Acad Sci USA 1994, 91(15):7149-7153.

31. Ng PC, Henikoff S: Predicting deleterious amino acid substitutions. Genome Res 2001, 11(5):863-874.

32. Sunyaev S, Ramensky V, Koch I, Lathe W, Kondrashov AS, Bork P: Prediction of deleterious human alleles. Hum Mol Genet 2001, 10(6):591-597.

33. Thomas PD, Campbell MJ, Kejariwal A, Mi H, Karlak B, Daverman R, Diemer K, Muruganujan A, Narechania A: PANTHER: a library of protein families and subfamilies indexed by function. Genome Res 2003, 13(9):2129-2141

34. Jambou R, Martinelli A, Pinto J, Gribaldo S, Legrand E, Niang M, Kim N, Pharath L, Volnay B, Ekala MT, Bouchier C, Fandeur T, Berzosa P, Benito A, Ferreira ID, Ferreira C, Vieira PP, Alecrim MG, Mercereau-Puijalon O, Cravo P: Geographic structuring of the Plasmodium falciparum sarco(endo) plasmic reticulum Ca2+ ATPase (PfSERCA) gene diversity. PLoS One 2010, 5(2):e9424.

35. Dharia NV, Bright AT, Westenberger SJ, Barnes SW, Batalov S, Kuhen K, Borboa R, Federe GC, McClean CM, Vinetz JM, Neyra V, Llanos-Cuentas A, Barnwell JW, Walker JR, Winzeler EA: Whole-genome sequencing and microarray analysis of ex vivo Plasmodium vivax reveal selective pressure on putative drug resistance genes. Proc Natl Acad Sci USA 2010, 107(46):20045-20050.

36. Weedall GD, Conway DJ: Detecting signatures of balancing selection to identify targets of anti-parasite immunity. Trends Parasitol 2010, 26(7):363-369.

37. Su X, Kirkman LA, Fujioka H, Wellems TE: Complex polymorphisms in an approximately $330 \mathrm{kDa}$ protein are linked to chloroquine-resistant $\mathrm{P}$. falciparum in Southeast Asia and Africa. Cell 1997, 91(5):593-603.

38. Ferdig MT, Cooper RA, Mu J, Deng B, Joy DA, Su XZ, Wellems TE: Dissecting the loci of low-level quinine resistance in malaria parasites. Mol Microbiol 2004, 52(4):985-997.

39. Prugnolle F, McGee K, Keebler J, Awadalla P: Selection shapes malaria genomes and drives divergence between pathogens infecting hominids versus rodents. BMC Evol Biol 2008, 8:223

40. Krief S, Escalante AA, Pacheco MA, Mugisha L, Andre C, Halbwax M, Fischer A, Krief JM, Kasenene JM, Crandfield M, Cornejo OE, Chavatte JM, Lin C, Letourneur F, Gruner AC, McCutchan TF, Renia L, Snounou G: On the diversity of malaria parasites in African apes and the origin of Plasmodium falciparum from Bonobos. PLoS Pathog 2010, 6(2):e1000765.

41. Liu W, Li Y, Learn GH, Rudicell RS, Robertson JD, Keele BF, Ndjango JB, Sanz CM, Morgan DB, Locatelli S, Gonder MK, Kranzusch PJ, Walsh PD, Delaporte E, Mpoudi-Ngole E, Georgiev AV, Muller MN, Shaw GM, Peeters M, Sharp PM, Rayner JC, Hahn BH: Origin of the human malaria parasite Plasmodium falciparum in gorillas. Nature 2010, 467(7314):420-425

42. King JL, Jukes TH: Non-Darwinian evolution. Science 1969, 164(881):788-798.

43. Scherf A, Petersen C, Carter R, Alano P, Nelson R, Aikawa M, Mattei D, da Silva LP, Leech J: Characterization of a Plasmodium falciparium mutant that has deleted the majority of the gametocyte-specific Pf11-1 locus. Mem Inst Oswaldo Cruz 1992, 87(Suppl 3):91-94.

44. Bozdech Z, Llinas M, Pulliam BL, Wong ED, Zhu J, DeRisi JL: The transcriptome of the intraerythrocytic developmental cycle of Plasmodium falciparum. PLOS Biol 2003, 1(1):E5.

45. Le Roch KG, Zhou Y, Blair PL, Grainger M, Moch JK, Haynes JD, De La Vega P, Holder AA, Batalov S, Carucci DJ, Winzeler EA: Discovery of gene function by expression profiling of the malaria parasite life cycle. Science 2003, 301(5639):1503-1508.

46. Volkman SK, Sabeti PC, DeCaprio D, Neafsey DE, Schaffner SF, Milner DA, Daily JP, Sarr O, Ndiaye D, Ndir O, Mboup S, Duraisingh MT, Lukens A, Derr A, Stange-Thomann N, Waggoner S, Onofrio R, Ziaugra L, Mauceli E, Gnerre S, Jaffe DB, Zainoun J, Wiegand RC, Birren BW, Hartl DL, Galagan JE, Lander ES, Wirth DF: A genome-wide map of diversity in Plasmodium falciparum. Nat Genet 2007, 39(1):113-119.

47. Mu J, Awadalla P, Duan J, McGee KM, Keebler J, Seydel K, McVean GA Su XZ: Genome-wide variation and identification of vaccine targets in the Plasmodium falciparum genome. Nat Genet 2007, 39(1):126-130.

48. Hartl DL, Volkman SK, Nielsen KM, Barry AE, Day KP, Wirth DF, Winzeler EA: The paradoxical population genetics of Plasmodium falciparum. Trends Parasitol 2002, 18(6):266-272.

49. Nei M, Gojobori T: Simple methods for estimating the numbers of synonymous and nonsynonymous nucleotide substitutions. Mol Biol Evol 1986, 3(5):418-426.

50. Mu J, Duan J, Makova KD, Joy DA, Huynh CQ, Branch OH, Li WH, Su XZ: Chromosome-wide SNPs reveal an ancient origin for Plasmodium falciparum. Nature 2002, 418(6895):323-326.

51. Li WH: Unbiased estimation of the rates of synonymous and nonsynonymous substitution. J Mol Evol 1993, 36(1):96-99.

52. Wootton JC: Non-globular domains in protein sequences: automated segmentation using complexity measures. Comput Chem 1994, 18(3):269-285

53. Hall N, Karras M, Raine JD, Carlton JM, Kooij TW, Berriman M, Florens L, Janssen CS, Pain A, Christophides GK, James K, Rutherford K, Harris B, Harris D, Churcher C, Quail MA, Ormond D, Doggett J, Trueman HE, Mendoza J, Bidwell SL, Rajandream MA, Carucci DJ, Yates JR, Kafatos FC, Janse CJ, Barrell B, Turner CM, Waters AP, Sinden RE: A comprehensive survey of the Plasmodium life cycle by genomic, transcriptomic, and proteomic analyses. Science 2005, 307(5706):82-86.

54. Tanabe K, Zakeri S, Palacpac NM, Afsharpad M, Randrianarivelojosia M, Kaneko A, Marma AS, Horii T, Mita T: Spontaneous mutations in the Plasmodium falciparum sarcoplasmic/endoplasmic reticulum Ca2 +-ATPase (PfATP6) gene among geographically widespread parasite populations unexposed to artemisinin-based combination therapies. Antimicrob Agents Chemother 2011, 55(1):94-100.

55. Dahlstrom S, Veiga MI, Ferreira P, Martensson A, Kaneko A, Andersson B, Bjorkman A, Gil JP: Diversity of the sarco/endoplasmic reticulum $\mathrm{Ca}(2$ +)-ATPase orthologue of Plasmodium falciparum (PfATP6). Infect Genet Evol 2008, 8(3):340-345

56. Gama BE, de Oliveira NK, de Souza JM, Santos F, de Carvalho LJ, Melo YF, Rosenthal PJ, Daniel-Ribeiro CT, Ferreira-da-Cruz Mde F: Brazilian Plasmodium falciparum isolates: investigation of candidate polymorphisms for artemisinin resistance before introduction of artemisinin-based combination therapy. Malar J 2010, 9:355.

57. Eshetu T, Berens-Riha N, Fekadu S, Tadesse Z, Gurkov R, Holscher M Loscher T, Miranda IB: Different mutation patterns of Plasmodium falciparum among patients in Jimma University Hospital, Ethiopia. Malar J 2010, 9:226.

58. Tahar R, Ringwald P, Basco LK: Molecular epidemiology of malaria in Cameroon. XXVIII. In vitro activity of dihydroartemisinin against clinical isolates of Plasmodium falciparum and sequence analysis of the P. falciparum ATPase 6 gene. Am J Trop Med Hyg 2009, 81(1):13-18.

59. Bertaux L, Quang le H, Sinou V, Thanh NX, Parzy D: New PfATP6 mutations found in Plasmodium falciparum isolates from Vietnam. Antimicrob Agents Chemother 2009, 53(10):4570-4571.

60. Imwong M, Dondorp AM, Nosten F, Yi P, Mungthin M, Hanchana S, Das D, Phyo AP, Lwin KM, Pukrittayakamee S, Lee SJ, Saisung S, Koecharoen K, Nguon C, Day NP, Socheat D, White NJ: Exploring the contribution of candidate genes to artemisinin resistance in Plasmodium falciparum. Antimicrob Agents Chemother 2010, 54(7):2886-2892.

61. Bacon DJ, McCollum AM, Griffing SM, Salas C, Soberon V, Santolalla M, Haley R, Tsukayama P, Lucas C, Escalante AA, Udhayakumar V: Dynamics of malaria drug resistance patterns in the Amazon basin region following changes in Peruvian national treatment policy for uncomplicated malaria. Antimicrob Agents Chemother 2009, 53(5):2042-2051. 
62. Ibrahim ML, Khim N, Adam HH, Ariey F, Duchemin JB: Polymorphism of PfATPase in Niger: detection of three new point mutations. Malar J 2009, 8:28.

63. Menegon M, Sannella AR, Majori G, Severini C: Detection of novel point mutations in the Plasmodium falciparum ATPase6 candidate gene for resistance to artemisinins. Parasitol Int 2008, 57(2):233-235.

doi:10.1186/1471-2148-11-257

Cite this article as: Gardner et al:: Protein-based signatures of functional evolution in Plasmodium falciparum. BMC Evolutionary Biology 2011 11:257.

Submit your next manuscript to BioMed Central and take full advantage of:

- Convenient online submission

- Thorough peer review

- No space constraints or color figure charges

- Immediate publication on acceptance

- Inclusion in PubMed, CAS, Scopus and Google Scholar

- Research which is freely available for redistribution

Submit your manuscript at www.biomedcentral.com/submit
() Biomed Central 